\title{
Toward a multidimensional understanding of culture for health interventions
}

\section{Citation}

Asad, Asad L., and Tamara Kay. 2015. "Toward a Multidimensional Understanding of Culture for Health Interventions." Social Science \& Medicine 144 (November): 79-87. doi:10.1016/ j.socscimed.2015.09.013.

\section{Published Version}

10.1016/j.socscimed.2015.09.013

\section{Permanent link}

http://nrs.harvard.edu/urn-3:HUL.InstRepos:24089946

\section{Terms of Use}

This article was downloaded from Harvard University's DASH repository, and is made available under the terms and conditions applicable to Other Posted Material, as set forth at http:// nrs.harvard.edu/urn-3:HUL.InstRepos:dash.current.terms-of-use\#LAA

\section{Share Your Story}

The Harvard community has made this article openly available.

Please share how this access benefits you. Submit a story.

Accessibility 


\title{
Toward a Multidimensional Understanding of Culture for Health Interventions
}

\author{
Asad L. Asad, M.A. \\ Tamara Kay, Ph.D. \\ Department of Sociology \\ Harvard University \\ Tel.: 414-243-1234 \\ Department of Sociology \\ University of New Mexico \\ Fax: 617-496-5794 \\ Tel.: 505-277-0860 \\ Fax: 505-277-8805 \\ Email: asad@fas.harvard.edu Email: tamarakay@unm.edu
}

Corresponding author: Asad L. Asad, Department of Sociology, Harvard University, 33 Kirkland Street, Cambridge, MA 02138. Email: asad@fas.harvard.edu

\begin{abstract}
Although a substantial literature examines the relationship between culture and health in myriad individual contexts, a lack of comparative data across settings has resulted in disparate and imprecise conceptualizations of the concept for scholars and practitioners alike. This article examines medical scholars and practitioners' understandings of culture in relation to health interventions. Drawing on 142 interviews with officials from three different nongovernmental organizations working on health issues in multiple countries-Partners in Health, Oxfam America, and Sesame Workshop - we examine how these practitioners' interpretations of culture converge or diverge with recent developments in the study of the concept, as well as how these understandings influence health interventions at three different stages-design, implementation, and evaluation - of a project. Based on these analyses, a tripartite definition of culture is builtas knowledge, practice, and change - and these distinct conceptualizations are linked to the success or failure of a project at each stage of an intervention. In so doing, the study provides a descriptive and analytical starting point for scholars interested in understanding the theoretical and empirical relevance of culture for health interventions, and sets forth concrete recommendations for practitioners working to achieve robust improvements in health outcomes.
\end{abstract}

\section{KEYWORDS}

United States; cross-contextual studies; culture; health; public health interventions; nongovernmental organizations; qualitative methods 


\section{INTRODUCTION}

That culture matters for health interventions is not a novel contention. Scholars and practitioners increasingly argue that an intervention's success depends on the extent to which it is tailored to the local cultural and political context (Anderson \& Olson, 2013; Castro et al., 2004; Kagawa-Singer \& Kassim-Lakha, 2003). This is particularly crucial for specialists working in developing regions, where adjusting an intervention to suit a specific cultural and political setting often determines whether the local government will allow its implementation and provide resources to institutionalize it (Asad \& Kay, 2014). Such an approach can impact long-term health outcomes (Banerjee et al., 2011; Farmer et al., 2006).

Despite consensus that culture can influence the design and delivery of health care interventions, what it means and how it matters for medical researchers and practitioners remains underexplored (Beckfield et al., 2013). Building upon insights from cultural anthropology, public health researchers, medical anthropologists, and sociologists have traditionally relied on a onedimensional definition of culture as meaning (Geertz, 1973) that refers to the shared codes, signs, and symbols to which collectivities of individuals attribute significance (Kleinman, 1978, 1987; Kleinman et al., 1978). Other work has expanded this definition to include "a set of guidelines... which individuals inherit as members of a particular society" (see also Furedi, 2006; Helman, 2001). For example, in the case of American Indian communities, scholars often construct culture as including social environments, education, and responses to colonialism (Anderson \& Olson, 2013; Goodkind et al., 2010). This conception has led some to conflate "culture" and "race" or "ethnicity" when examining population-level health trends, describing the emergence of essentialist racial or ethnic subcultures with their own concepts, rules, and 
social organization (Becker et al., 2004; Betancourt et al., 2003; Fullwiley, 2007; Lamont \& Small, 2008).

As criticism mounted that these one-dimensional understandings of culture are vague and inaccurately applied in medical training and practice (Kagawa-Singer \& Kassim-Lakha, 2003), scholars began to define the concept in new ways. Most researchers recognized culture as dynamic and heterogeneous within and across settings and understood it as providing individuals with the "tools" or "rules" required to take action but not necessarily driving it (Shim, 2010; see Swidler, 1986). They also began to focus on individual cultural contexts. This approach is perhaps best exemplified by community-based participatory research (CBPR), which emphasizes that partnerships between academics, practitioners, and local communities-with interventions adjusted to individual values, attitudes, beliefs, languages, and corresponding behaviors that are often idiosyncratic across groups (Trickett et al., 2011: 1413)—can spur community members' participation in public health advocacy and effect structural changes aimed at eliminating health disparities (Israel et al., 2010: 2094). An abundance of case studies from myriad interventions worldwide has demonstrated CBPR's potential (see Viswanathan et al., 2004 for a review).

Although generalizations about how culture operates within and across settings to shape individuals' health behaviors should be avoided (Helman, 2001; Kleinman, 1978), the proliferation of single-sited, culturally-tailored interventions worldwide has prevented a meaningful dialogue between researchers and practitioners interested in understanding the relationship between culture and health (Cockerham, 1981; Salant \& Lauderdale, 2003). Instead, several "ontological myopias" have emerged whereby scholars and practitioners make assumptions about what culture means and how it operates in the resource-poor contexts they study (Rodríguez-Muñiz, 2015); pinpointing how cultural predispositions relate to health 
outcomes is thus viewed as almost impossible (Pescosolido \& Olafsdottir, 2010; Weiss, 2001). In short, there is a need to define culture in a way that not only accounts for local variation, but that also provides a concrete framework for those interested in implementing health interventions across diverse geographic, ethno-racial, and political settings.

This article interrogates medical scholars and practitioners' understandings of culture. Specifically, we examine along what dimensions they conceive of culture, as well as how their interpretations of culture influence three different stages-inception, implementation, and evaluation - of a health project. We do so by drawing on 142 interviews with representatives from three nongovernmental organizations (NGOs) working on health issues in a variety of countries. Understanding how these actors think about culture's role in health interventions will serve to develop a shared definition of culture that can be applied in both research and practice.

\section{METHODOLOGY}

\section{Study Settings}

We rely on in-depth, semi-structured interviews conducted with representatives from three NGOs working on health issues worldwide in order to understand the role of culture at different stages of a health intervention. Our approach maximizes variation in both the type of health project and the cultural context under scrutiny; this enables us to identify how culture is defined and how it matters across settings (Beckfield et al., 2013; see also Lamont et al., 2014), which is important to generate robust and generalizable qualitative findings (Yin, 2009).

The first organization is Oxfam America (OA), which is based in Boston, Massachusetts and works in ninety-four countries on projects relating to public health, community finance, gender equality, and access to potable water. One project, Saving for Change (SfC), provides “a locally appropriate tool" for villagers in thirteen countries to manage their finances in order to 
guard against shocks to income such as food or health expenses; malaria education is also part of some of the programs. In a recent evaluation of the organization's largest SfC site in Mali, significant improvements in food security and malaria knowledge were detected in treatment villages when compared to the control villages (Bureau of Applied Research in Anthropology, 2013). Similar results were found in El Salvador (Devietti \& Matuszeski, 2008).

Partners in Health (PIH), also based in Boston, is the second case. PIH pioneered the community-based care model, which complements conventional clinical services with homebased care. For example, treatment for tuberculosis and HIV/AIDS has led to substantial improvements in patient well-being in La Cange, Haiti (Farmer et al., 2001) where, in many cases, services to rural communities would otherwise not be available (Jerome \& Ivers, 2010). A similar program used to control the spread of malaria in the Democratic Republic of the Congo led to a $50 \%$ decrease in morbidity in treatment villages when compared to the control (Delacollette et al., 1996).

The third case is the educational nonprofit Sesame Workshop (SW), based in New York, which produces the children's television program, Sesame Street, and local versions around the world, called "coproductions." In addition, SW engages in health education projects with partners in developing countries. Research shows robust improvements in knowledge and behavior along various dimensions of public health, including malaria prevention in Tanzania (Borzekowski \& Macha, 2010), hand-washing in India (Policy Innovations, 2010), and road safety in Japan (Borzekowski \& Henry, 2010).

\section{Data Collection}

From 2008 through 2014, the senior author conducted 113 semi-structured, in-depth interviews with representatives from SW in New York, as well as their local partners in Mexico, 
Brazil, Colombia, Israel, Palestine, Jordan, India, Nigeria, and with members of the Gulf Cooperation Council (Bahrain, Kuwait, Omar, Qatar, Saudi Arabia, and the United Arab Emirates). The senior author, with a team of research assistants, also conducted 29 semistructured, in-depth interviews with key officials from OA and PIH at their respective Boston offices and by phone between September 2010 and February 2014.

With permission and assistance from the leadership of each organization, we recruited respondents from all three NGOs who had international work experience using a purposeful sampling approach (Seidman, 2012). We interviewed officials from as many levels as possible until we reached saturation in how respondents conceptualized, accommodated, and transformed culture at all stages of an intervention. Although confidentiality concerns preclude us from disclosing respondents' exact job descriptions, participants included high-ranking officials, project managers, and lower-level staff from all three organizations. The interview guide-part of a larger study on globalization, culture, and the politics of transnational NGO collaborationsincluded questions for all respondents regarding their professional background; how local partners are chosen; how a project evolves from inception to termination; and how each organization engages with state institutions at the local, regional, and national levels. Our interviews $(\mathrm{N}=142)$ - a majority of which come from SW given the organization's size and the scope of its health projects - lasted between one and seven hours and had a median length of 3 hours (interviews with respondents who were relatively new to an organization and/or who had little international work experience were generally shorter). Interviews were recorded and transcribed, totaling over 200 hours of audio and generating over 3,000 single-spaced pages of transcripts. The Institutional Review Board at Harvard University approved this study. We have decontextualized the data where appropriate to ensure respondents' confidentiality. 


\section{Data Analysis}

Although we wanted to understand how medical scholars and practitioners conceptualize culture when conducting a health intervention, we did not code our data with any preconceptions about what we might find. Rather, we relied on an inductive and iterative approach and only explored themes that emerged organically from our analyses (see Glaser \& Strauss, 2009). We first read all interviews separately in order to acquaint ourselves with the data. Formal analysis then began, following the grounded theory approach of Miles and Huberman (1994). We read through the interviews once more in order to systematically generate codes related to culture and health across contexts. We found that asking about respondents' experiences in their respective organizations elicited additional information about culture and health at different points in the interview. Our analysis reflects all these sources of information, not just the answer to a single question, "How do you think about local culture when carrying out your work?"

After reading all interviews at least twice, both authors discussed the themes for which we would code the data. It was during this time when we realized that how our respondents understood culture was not always consistent with contemporary understandings of the concept in the social sciences. We finally coded transcripts using Atlas.ti, using the codes that reflected the emerging patterns we had previously identified. In particular, we coded for past professional experience in health interventions, definitions of culture, how culture did and did not matter in various health projects, and any discussions of project success and failure when it pertained to culture. We identified three phases over the course of a health intervention at which respondents described the importance of taking local culture into account: when designing, implementing, and evaluating a health project.

\section{FINDINGS}


The following sections highlight our findings from our analyses of respondents' experiences with designing, implementing, and evaluating various health interventions. In particular, we use illustrative examples to identify how respondents' perceptions of culture at the various stages of an intervention can influence the project's success or failure. We also point out the mutually-constitutive dialectic that exists between structural constraints and more traditional definitions of culture (as symbols, norms, and meanings). Following the presentation of our findings, we build on past work in cultural sociology and suggest a nuanced, multidimensional definition of culture as cultural knowledge, practice, and change.

\section{Conceptions of Culture in Designing Health Interventions}

In this section, we demonstrate how incorporating culture into the design of a health intervention is critical for project efficacy. By distinguishing culture from local governance, and taking into account cultural diversity and the semiotic importance of local cultural symbols, practitioners can increase the likelihood of project success.

\section{$\underline{\text { Culture and Local Governance }}$}

Respondents explained the importance of understanding local needs and respecting local culture when planning a health intervention. While all foregrounded the importance of local participation in a project, some equated understanding culture with understanding local power structures. For example, when asked about the benefits and challenges of hiring almost all local staff, an OA official explained:

The benefit is cultural awareness. Cultural awareness is really important for political maneuvering. It's not just, you know, how to serve the tea, [but] it's [also] how to get in to see the minister and who to deal with - who are the minister's friends and who are the minister's enemies? - and all that. That kind of political treatment is so important for designing a program. Those benefits, I think, are pretty clear.

As this example reveals, although respondents placed a high value on local knowledge, they often conflated local culture and local governance. While understanding local power dynamics is 
crucial to obtaining buy-in and support of local government officials, it is distinct from understanding shared local meanings, which respondents described as critical when designing interventions intended to have positive health outcomes. A PIH respondent explained how a pilot project to encourage women in Southern Africa to give birth at health clinics likely would have failed if local women had not shared cultural traditions regarding childbirth:

There's a good example of something [in Southern Africa] that was an easy fix. For people in [Southern Africa], it's very important to bury the placenta at home because that's like your root to your home. So-I don't remember if it was the community health instructors who told us this-but then it was like, "OK, everyone gets a plastic bag to take their placenta home in." No problem! So, something that could have prevented women from actually deciding to deliver in a facility was actually an easy fix while still making sure they could still maintain their cultural traditions.

Conflating culture and local governance may reify social hierarchies (Watkins \& Swidler, 2013) and result in top-down health intervention models that neglect seemingly-small local needs. In particular, conceptions of culture as local governance may undermine a health intervention at the outset by privileging the knowledge of local officials and failing to reflect or address the needs of a diversity of community members (see, e.g., Angotti et al., 2014).

\section{$\underline{\text { Culture and Diversity }}$}

Respondents generally recognized that culture is not monolithic, and that there exists tremendous variation in experiences and meanings across gender, class, and ethno-racial groups within countries or regions. As an SW official explained: "We talk about issues of language diversity, cultural diversity, religious diversity, all of these things, because these countries are so vast and, within each country, there are so many different religions and languages and other things that we have to focus on." Failure to design health interventions that account for local cultural diversity can derail efforts to improve health outcomes. An OA official described how, when a local Thai foundation surveyed the participants of an OA project for poor people living with HIV/AIDS, the results were surprising, even for Thai doctors: 
They asked people who were in the program, all of whom were HIV positive, "What's your number one need right now?" And, as you might expect, medical doctors predicted they wanted access to antiretroviral drugs. They did, but that was number three on their list. What do you think their highest priority was? Their number one need, or expressed need, was nondiscrimination. They wanted to be treated like everyone else. [...] They wanted to go to the market and not get heckled or shunned. [...] So the psychosocial benefits of this program were really what they identified as their number one value. This is the first lesson for us as development practitioners when we think about impact. Let's work with our primary agents of change and collectively define what we want to measure. It may not be what we obviously think about as outsiders.

As this example suggests, although local partners are usually able to identify the needs of the local population, they may also be more affluent, educated, and from a more privileged social position than the target population. Utilizing advisors with personal experience in, or knowledge across, class, ethno-racial, religious, or other socially-meaningful dimensions to help navigate cultural boundaries increases the likelihood of an intervention's viability and sustainability.

\section{$\underline{\text { Culture and Local Adaptation }}$}

Examining a health intervention that did not succeed strengthens our analysis and affirms the importance of addressing cultural diversity, particularly through local adaptation. Research measuring the impact of SW's Healthy Habits for Life health education curriculum (centered on nutrition, healthy eating habits, and exercise) in the United States shows that it has a positive effect on children's eating habits and levels of physical activity (Kotler et al., 2012; Ritchie et al., 2010). Despite the curriculum's success in the U.S., it was unsuccessful when introduced in

Brazil because SW did not locally adapt the content, as one local partner explained:

We have a different culture in Brazil, with food and everything. It's simple. What's the main food in Brazil? Rice, beans, salad, and beef. All the projects that we get from Sesame are based on a different culture-an American culture, not a Brazilian one. So I get all the booklets from Sesame with recipes that are not used here in Brazil. When I asked them to adapt something, they told me, "Oh, it's too expensive for the educators to adapt this." So we would have to adapt this in Brazil ourselves. Why am I going to pay for someone in Brazil to do this? I don't have to adapt something from Sesame. We can do it in Brazil with local nutritionists, local doctors.

SW officials agreed with their Brazilian partners' assessment of their failure to take into account

local needs, as one New York official reflected:

Looking back, if we all had a clearer picture of what we wanted to accomplish, I think a lot of that kind of the struggle could have been minimized. That was the hugest learning experience for everyone. If we had a 
clearer map of what we wanted to do...I think, sometimes, we're eager to break into a particular country without really assessing what the needs are.

In this example, although food itself is not culture, it represents a broader cultural symbol that is authentically Brazilian and socially meaningful as individuals attempt to make sense of the health intervention with respect to their own lives (Van Leeuwen, 2005). It also suggests the importance of adapting a project to local cultural needs.

\section{Conceptions of Culture in Implementing Health Interventions}

Although planning is important, we argue that even the most carefully-planned projects are unlikely to succeed if culture is ignored during their implementation. In particular, we suggest that failure to separate culture from issues of non-compliance stemming from infrastructure and stigmatization can derail even the most well-intentioned health interventions.

\section{Culture and Infrastructure}

Even after extensive planning, a health intervention is more likely to fail without local support and participation, both of which are crucial for project legitimation and success during its implementation. However, many problems that appear to be rooted in culture are actually issues that stem from a lack of access to resources or limitations in local infrastructure. SW recently launched a health education curriculum in Nigeria, Bangladesh, and India intended to generate a simultaneously global and local sanitation behavioral change program. An SW official explained the challenge the organization faces in light of each country's distinct sanitation requirements and infrastructural shortcomings: "It's a behavioral change campaign, but all the

three countries have said that the infrastructure does not support behavioral change." She elaborated: "People will not stop defecating in the open unless they find toilets that are maintained and clean that they can use. That's the gap. But the project says that we must change behaviors for children and have them go to toilets. Now, we are seeing there are no toilets." 
SW's local Indian partners addressed these infrastructure problems in a creative way by introducing a community participation element into a different health intervention. A local SW official explained how her team responded when, during a community radio program on handwashing, a caller suggested soap was unnecessary:

\begin{abstract}
Most people will say that you must wash hands with soap and water. But in India, in many of the cultures, you can also wash hands with ash. During the program, we were telling people to wash hands with soap and water, but somebody [called in and] said, "You can also wash with ash." So we realized there's a problem. It's not something that's wrong with anybody. It's a belief. But if my program starts addressing the belief, I have lost track [of my goal] because mine is a children's program. I cannot start telling the community, "No, you should not wash hands with ash." That's not why we are there. We are there to give the right message, and we cannot argue with the community. We may tell them later why you should not wash hands with ash, but not at that point. So the point is important. That 15-minute program is critical for us to give the right message. If we lose that, we've lost the entire thing. Now, in addition to the programming and all of that, we also supported each community radio station in doing six community-level events so they could call their local politician and say, "Look, there are no soaps in the schools. You have the money. Please give soap."
\end{abstract}

Although the respondent considered the belief to be cultural, she also recognized that changing that belief required resources, and her team introduced a way to try to acquire them by expanding the intervention. A PIH official offered her reflections on the relationship between culture and resources: "I do think that, at the root of all of the work that we do, there is a sort of definite sense that a great deal of this is about lack of access to resources rather than a significant belief in one thing or another, or that the beliefs had come from this lack of access." Given the myriad structural constraints and obstacles that can arise and stymie implementation (Cockerham, 1981), it is important for practitioners to eliminate those that arise from a failure to distinguish problems of culture from problems of infrastructure.

\title{
Culture and Stigma
}

In addition to addressing issues of infrastructure, implementing a health intervention in a way that is sensitive to individuals' health-seeking behavior is also crucial for success. One PIH official described how various organizations erred in establishing HIV/AIDS testing sites in Haiti 
because they reinforced the social stigma associated with testing. Very few people utilized the testing sites, as the official explained:

\begin{abstract}
Stigma is a barrier for us, and it makes things complicated. It gets in the way of patients coming to clinics, for example. HIV clinics were put up everywhere. And they had blue roofs, and you knew that they were HIV clinics. And there was voluntary testing and counseling well before there was treatment [for HIV/AIDS]. Now, I don't know about you, but if I knew there was no treatment for a potentially-deadly and sexually-transmitted disease, I am not sure that I would go and get tested. I wouldn't choose to prioritize it as part of my day and then walk there and be seen walking in.
\end{abstract}

As the official suggests, using culture to explain Haitians' reluctance to get tested for HIV misses the underlying problem of social stigma: "It's like people would say, 'Well, there's stigma associated with HIV. It's cultural; people won't go.' Because [the testing sites] were almost empty." PIH officials decided to eliminate the stigma of HIV testing by incorporating testing into regular health visits: "What we found was that, if we started to put HIV testing as part of primary health clinics rather than separate facilities that had a big sign on the top that said, 'HIV tested here,' we took some stigma away and people were keen to be tested." PIH officials thus underscored the importance of being flexible in the face of structural constraints by reducing the stigma associated with utilizing services (Link \& Phelan, 2006; Metzl \& Hansen, 2014).

\title{
III. Conceptions of Culture in Evaluating Health Interventions
}

For an intervention to achieve and sustain improvements in various health outcomes over time requires not only project institutionalization, but also a framework for stimulating cultural change. Below, our observations of program evaluations identify how conflating culture with non-compliance can threaten outcomes. We then illustrate how an intervention sensitive to local culture can change knowledge, attitudes, and behavior; facilitate project institutionalization; and generate robust improvements in health outcomes in the long term.

\section{$\underline{\text { Culture and Non-Compliance }}$}


Taking projects to scale is only helpful if the health intervention is institutionalized in such a way that local communities continue to benefit from it once international fieldworkers withdraw. Community-level support is especially important, as PIH officials realized when they established a treatment center for tuberculosis in Cange, Haiti. Many PIH fieldworkers were concerned that some patients were not using the services, a phenomenon many initially attributed to "non-compliance" resulting from cultural factors. However, as one official described, this "non-compliance" was really the result of larger socio-structural factors that complicated uptake (see Barnhoorn \& Adriaanse, 1992; Metzl \& Hansen, 2014):

We went down into the communities and, of course, they didn't have transportation, they felt too sick, and they couldn't leave their children. So they didn't come to the clinic. Is that non-compliance, or do we help them access the healthcare? If that is your mission, you have got to find the ways to get to do what it is you say you are going to do and not say, "The patients didn't come, so it's their fault."

Awareness of the socio-structural constraints to health care access, utilization, and sustainability is important when delivering care to socially-vulnerable populations. PIH officials responded to these constraints by using community health workers who understand the structural issues and are trained to address them, as one PIH official explained: "If we want this treatment to be effective, we have to base it in the community, so that's when we started hiring locals and training them as community health workers." By engaging the local community, PIH projects had a greater positive impact on health outcomes and could therefore be more effectively institutionalized. As this case reveals, like issues of stigma and infrastructure, many problems of non-compliance that appear to be cultural are actually rooted in larger structural inequalities.

\section{Culture and Changing Knowledge, Attitudes, and Behavior}

Many respondents articulated how politically controversial promoting changes in attitudes and behavior around health can be. As one OA official explained:

People are very sensitive when you're trying to change culture or social norms. That's a very difficult issue, and it has to be well thought out before you do it. The potential for doing great harm is always there - that's 
part of the risk assessment. That's why you get people you're trying to help to have a voice, people from the local partners to have a voice, because they know these scenarios very well.

Unlike in Brazil, when SW launched Healthy Habits for Life in Mexico in 2007 and in Colombia in 2010 to address the dual problems of obesity and malnutrition in the region, the organization adapted the intervention by addressing local needs and reflecting local culture. A Colombian partner described:

We were able to use what was already made in New York, and at the same time, we were also able to include local characteristics. For example, in terms of diet, we were told that we needed to focus on eating diversified foods. It wasn't just access to healthy food, but also the diversity of the food. It also had to do with Colombian culture because we consume a lot of carbohydrates and meat; however, Colombians are not used to eating a lot of vegetables and fruits. The Children's Heart Foundation [a local partner] has really dedicated themselves to promoting the prevention of diseases due to poor diet and exercise on children. They contributed to the messages that were used in the Colombian Plaza Sésamo; they did not only come from outside the country.

SW's local adaptation of the Healthy Habits for Life curriculum and its prioritization of working closely with governments and local NGOs resulted in a successful intervention in these countries. Research shows that children exposed to the intervention had significant improvements in knowledge, attitudes, and habits related to healthy eating and active lifestyles (Céspedes et al., 2013; CINCO, 2009) that remained even one year post-intervention.

\section{DISCUSSION}

While much debate remains in the social sciences about what constitutes culture, the disagreement largely centers on issues of knowledge and action. When viewed as knowledge, culture refers to a shared set of ideologies, beliefs, values, or norms that cultural sociologists use to describe groups' justifications for action (Camic et al., 2012; Lamont \& Molnár, 2002; Swidler, 1986). When viewed as action, culture is defined as shared behavior, practice, or pragmatics that cultural sociologists use to explain what groups of individuals do (Patterson, 2004; Vaisey, 2009, 2014). Patterson (2014: 4-15) unifies these distinct perspectives and defines culture as the conjugate of two interconnected processes: 
The first is a dynamically stable process of collectively made, reproduced, and unevenly shared knowledge about the world that is both informational and meaningful. [...] The [second] interactional or pragmatic component of culture refers to the ways people use cultural knowledge in their interactions, with such usage itself representing a kind of cultural knowledge.

We build upon Patterson's work and, relying on our inductive categorization of practitioners' definitions of culture presented above, extend his definition to include three distinct dimensions: cultural knowledge, cultural practice, and cultural change. We summarize our theoretical model in Table 1 and more concretely outline each category below.

\section{[Table 1 about here.]}

Before proceeding, however, it is important to emphasize that we do not mean this typology to be deterministic. While we find broad correspondence between cultural knowledge, practice, and change with the design, delivery, and evaluation of a health intervention, respectively, we recognize that these dimensions are often overlapping and interdependent in practice. Indeed, knowledge and practice inform change, and more long-lasting change is likely when we adjust how we relate knowledge and practice to particular sites of intervention.

\section{Cultural Knowledge and Program Design}

Cultural knowledge is the first dimension of culture that matters for health interventions, and it includes all the shared ideologies, beliefs, values, norms, and meanings to which groups of individuals attribute significance (cf. Geertz, 1973). These shared understandings provide "predictability and regularity, coordination equilibria, continuity, and meaning" through which individuals act and interact and, as such, represent constitutive social practices (Patterson, 2014: 7). While culture varies both within and across contexts, health interventions that address and accommodate the shared meanings that individuals use to make sense of themselves and their world in any given setting are more likely to be effective than those that do not. 
We relate cultural knowledge to the design of health interventions. Although tailoring health projects within and across settings may pose complications for taking them to scale, here we highlight the importance of flexibility: while randomized control trials are often considered the gold standard for most NGO-led interventions (Banerjee et al., 2011; Watkins \& Swidler, 2013), they purport to hold culture as constant and attempt to manipulate behavior by offering incentives that make individuals' short-term participation in a project more likely (Bamberger et al., 2011). However, addressing socially-meaningful cultural beliefs in any setting — as PIH did by allowing mothers to take home placentas in Southern Africa-can mean the difference between a health project's success and failure. Thus, rather than standardize the process by which practitioners arrive at a health outcome, it is more prudent to hold the desired outcome as fixed and allow how it is achieved to vary according to individuals' shared ideologies, beliefs, values, norms, and meanings.

\section{Cultural Practice and Program Implementation}

Cultural practice is the second dimension of culture that influences health interventions. Not only must groups of individuals share cultural knowledge, but through their interactions with one another, they must also select the knowledge they need and what they do with it. While individuals' choices are generally enabled or constrained by structural forces, individuals also have the potential to facilitate structural and cultural changes (Patterson, 2014: 7); these dynamics are thus mutually constitutive. Successful health interventions are those that respect individuals' shared ideologies, beliefs, values, norms, and meanings and leverage them to take advantage of, or overcome, the structural limitations to individuals' health-seeking behavior.

We link this dimension of culture to the implementation of health interventions. In addition to involving local experts when planning a project, a health intervention requires 
sustained local support that provides it with legitimacy. When SW failed to adapt the Healthy Habits for Life curriculum to the Brazilian context, the project did not succeed. Although structural barriers to the successful implementation of a health intervention should be identified and addressed, practitioners should be careful not to conflate infrastructure and culture. Doing so risks attributing the beliefs and practices of small numbers of people-even when they stem from a lack of resources and opportunities - to general populations. One PIH official suggested that this finding holds in resource-abundant contexts as well, as evidenced by the Western "cultural practice" among some well-educated middle class mothers who refuse to vaccinate their children. Such anecdotes should give practitioners pause before labeling a behavior "cultural."

While an NGO may not be able to manage all structural impediments to individuals' health-seeking behaviors, it can ensure that its interventions are implemented in a way that is sensitive to these behaviors. In many settings, stigma is attached both to illness and treatment (Corrigan, 2004; Fay et al., 2011; Link \& Phelan, 2006), which may limit health-seeking behavior. By being flexible in the field, and merging HIV/AIDS testing with primary care checkups, PIH reduced much of the social stigma associated with participating in the health intervention. Given the relationship between stress, social status, and stigma, through which macro-level population health outcomes may be explained (Marmot, 2004; Phelan et al., 2014), efforts to undermine stigma can improve health-seeking behaviors and overall outcomes.

\section{Cultural Change and Program Evaluation}

The final dimension we outline as important to health interventions is cultural change, or the idea that cultures constantly evolve through a dynamic relationship between cultural knowledge and cultural practice. As groups of individuals accumulate new knowledge about effective health practices and effectively translate this knowledge into everyday behavior, 
cultural changes that accommodate these new beliefs and practices can occur if the intervention is appropriately tailored to the target population.

We link this component of culture to health outcomes over time. While research shows that health interventions generally succeed in the short-term (Bero et al., 1998; Campbell et al., 2000; Glanz et al., 2008; Liberati et al., 2009), long-term success depends on the project's institutionalization and its ability to change behavior. Interventions that actively recruit community members from all socioeconomic strata and address cultural diversity are more likely to be institutionalized than those that do not rely on a broad base of local support. Establishing smaller health interventions in local communities allowed PIH to involve more locals in their work, basing healthcare in the community and increasing the likelihood of institutionalization.

The goal of an intervention should not be to impose Western or otherwise hegemonic ideals on the target population. Health interventions should nevertheless attempt to bring about a cultural shift that alters the relationship between cultural knowledge and cultural practice such that health becomes both knowledge and practice. Here, SW's Healthy Habits for Life campaigns in Mexico and Colombia provide useful case studies. SW's local partners customized materials created for a U.S. audience to address local needs and practices. Such adaptation entailed the inclusion of cultural symbols - diverse foods, for example - that helped local populations make sense of the health intervention vis-à-vis their daily lives. While the mechanisms driving this cultural change likely vary across contexts, leveraging culture such that it results in sustained improvements in health is a cornerstone of health care delivery (Andersen, 1968, 1995; Good et al., 2011).

Toward a Multidimensional Understanding of Culture for Health Interventions 
Shifting to a multidimensional conception of culture for health interventions is important for three reasons. First, it extends previous scholarship on culture and health by clarifying both culture's descriptive and analytical purpose for health interventions. Culture, whose definition varies based on the cultural context under scrutiny, has been used to evaluate how individuals think about and utilize health care, though little work has provided a systematic framework for how this matters on the ground (Dubbin et al., 2013; Trickett et al., 2011). While we "embrac[e] the notion that people, places and professions matter in all times and in all places, even as they play out differently in different societies" (Pescosolido \& Olafsdottir, 2013: 269), the proliferation of site-specific definitions of culture fall short of providing other researchers and practitioners with a framework for how to conceive of culture, and how to apply it, in other contexts. Our model provides a definition of culture that is flexible across settings - the shared ideologies, beliefs, values, norms, and meanings to which groups of individuals attribute significance — and also avoids essentializing particular social groups. This simultaneously broad but localized view of culture reveals how flexibility in the design of health interventions could yield robust improvements in health outcomes.

Second, a multidimensional understanding of culture can help explain variation in health care utilization and health-seeking behavior in a more nuanced way. While our model is sensitive to group-level differences in health-seeking behavior, it also recognizes that economic and political realities enable or constrain behavior and suggests how those designing health interventions can actively strategize to take advantage of, or overcome, these differences. For example, if the goal of a health intervention is to reduce the incidence of HIV/AIDS, it is important to recognize that appropriating prevention and treatment models developed in the United States-where social factors such as poverty, gender inequality, and institutionalized 
racism make the poor disproportionately vulnerable to the disease — will not necessarily translate successfully in Haiti or Rwanda, where these same forces combine with great social upheaval to limit treatment options for the countries' most vulnerable citizens (Farmer et al., 2006: 1688). Effectively balancing group-level cultural rules and macro-level structural constraints-as PIH did with its tuberculosis testing sites in Haiti — can lead to the successful institutionalization of a health intervention and the diffusion of health-seeking behavior through social networks.

Finally, a multidimensional conception of culture provides a more nuanced understanding of how to achieve cultural change. Many scholars, practitioners, and local participants alike are justifiably wary of projects - especially those initiated by Western NGOs or by more powerful groups within a country - that seek to change relatively-disadvantaged populations' behaviors (see, e.g., Airhihenbuwa, 1995). However, extant research often overlooks how cultural change driven by the target population can yield long-term improvements in health outcomes. This oversight is due, in part, to a lack of cross-national qualitative data capable of observing this dynamic on the ground (Beckfield et al., 2013). Our framework details how a health intervention that is designed and implemented with the support of the target community can result not only in its successful institutionalization, but also produce an internal cultural shift-rather than an external cultural imposition — that alters the relationship between cultural knowledge and cultural practice such that health becomes both knowledge and practice.

\section{Reflections on Community-based Participatory Research}

We recognize the similarities between how the NGOs we studied operate and the CBPR framework described in the introduction. However, our goal in this article has been to introduce a theoretical model of culture that improves upon the one-dimensional definitions that characterize much of the extant research on health interventions. We thus build upon or 
differentiate ourselves from CBPR in three crucial ways. First, CBPR relies primarily on thick descriptions of culture. Our model understands culture as a constitutive social practice based on shared ideologies, beliefs, values, norms, and meanings that act as a probabilistic causal force in shaping health outcomes (Patterson, 2014: 7). Second, CBPR emphasizes extreme contextualism but overlooks "the effects that more macro-level forces, such as state and national policies and ideologies, have on relevant aspects of community life" (Trickett et al., 2011: 1413). Our framework not only illuminates how structural forces enable or constrain people's choices, but also that individuals have the potential to effect structural and cultural changes. Finally, CBPR overlooks that health interventions are, at root, mutually constitutive. The principal texts outlining the CBPR approach emphasize that an intervention must relate to the local community (Minkler \& Wallerstein, 2011) but ignore how the community must also relate to the health intervention. Simply accommodating local culture is unlikely to bring about changes in health behaviors if the dynamic between a health intervention and its intended utilizers is lacking.

\section{CONCLUSION}

In this article, we have proposed a more nuanced understanding of culture in relation to health interventions. We have encouraged scholars and practitioners to shift to a multidimensional conception of culture as knowledge, practice, and change. The first dimension, cultural knowledge, includes all the shared ideologies, beliefs, values, norms, and meanings to which groups of individuals attribute significance. We relate cultural knowledge to the design of health interventions. Cultural practice is the second dimension, and it refers to how groups of individuals share and deploy cultural knowledge. We link this dimension of culture to the implementation of health interventions. Finally, the third dimension is cultural change, or the 
idea that cultures constantly evolve through a dynamic relationship between cultural knowledge and cultural practice. We link this component of culture to health outcomes over time.

Our data reveal that, rather than view culture across these multiple dimensions, practitioners generally understand it along only one or two. These flat understandings of culture have important implications for the design, delivery, and evaluation of a health intervention. For example, when designing a project, we highlighted how conflating culture and local governance, as well as ignoring cultural diversity and the meanings associated with local cultural symbols, can threaten an intervention's success. We also argued that, even when a project is carefully planned, it might still fail if practitioners do not separate culture from issues of non-compliance related to infrastructure and stigmatization. And, finally, we illustrated how a health intervention sensitive to local culture could bring about changes in knowledge, attitudes, and behavior; make project institutionalization more likely; and facilitate cultural changes that improve health outcomes. In so doing, our goal has been to provide a descriptive and analytical starting point for scholars interested in understanding the theoretical and empirical relevance of culture for health interventions, and to set forth concrete recommendations for practitioners working to achieve short and long-term improvements in health outcomes. 


\begin{tabular}{|c|c|c|}
\hline Process & Definition & Practical Examples \\
\hline Cultural Knowledge & $\begin{array}{l}\text { The shared ideologies, beliefs, values, norms, } \\
\text { and meanings to which groups of individuals } \\
\text { attribute significance, all of which underlie } \\
\text { how individuals act and interact }\end{array}$ & $\begin{array}{l}\text { Design flexible interventions, fixing the } \\
\text { desired outcome but varying the process } \\
\text { by which it is achieved } \\
\text { - Avoid manipulating behavior by offering } \\
\text { incentives; rather, address socially- } \\
\text { meaningful culture beliefs in any setting to } \\
\text { facilitate and encourage participation } \\
\text { - Involve local stakeholders - community } \\
\text { leaders, academics, and government } \\
\text { officials-in project design, and include } \\
\text { perspectives from a diverse set of social } \\
\text { positions }\end{array}$ \\
\hline Cultural Practice & $\begin{array}{l}\text { How groups of individuals select the cultural } \\
\text { knowledge they need and what they do with it }\end{array}$ & $\begin{array}{l}\text { - Do not to conflate issues that stem from } \\
\text { resource disparities or a lack of } \\
\text { infrastructure with culture } \\
\text { - Avoid dismissing local cultural beliefs; } \\
\text { instead, remain focused on diffusing the } \\
\text { key lessons from the health project } \\
\text { - Remain vigilant for potential sources of } \\
\text { social stigma; do not unintentionally } \\
\text { isolate the target population as "different" } \\
\text { from the larger population }\end{array}$ \\
\hline Cultural Change & $\begin{array}{l}\text { The idea that cultures constantly evolve } \\
\text { through the dynamic relationship between } \\
\text { cultural knowledge and cultural practice }\end{array}$ & $\begin{array}{l}\text { Base health interventions in the } \\
\text { community rather than in places } \\
\text { inaccessible to the target population } \\
\text { - Actively engage with the local community } \\
\text { to maintain local buy-in and to promote } \\
\text { project institutionalization } \\
\text { Recognize that changing culture or social } \\
\text { norms is a sensitive topic; avoid imposing } \\
\text { treatment models that do not reflect local } \\
\text { needs or culture }\end{array}$ \\
\hline
\end{tabular}




\section{References}

Airhihenbuwa, C.O. (1995). Health and culture: Beyond the Western paradigm: Sage. Andersen, R.M. (1968). Behavioral Model of Families' Use of Health Services.

Andersen, R.M. (1995). Revisiting the behavioral model and access to medical care: does it matter? Journal of Health and Social Behavior, 1-10.

Anderson, K.M., \& Olson, S. (2013). Leveraging Culture to Address Health Inequalities: Examples from Native Communities". Roundtable on the Promotion of Health Equity and the Elimination of Health Disparities: Institute of Medicine.

Angotti, N., Frye, M., Kaler, A., Poulin, M., Watkins, S.C., \& Yeatman, S. (2014). Popular Moralities and Institutional Rationalities in Malawi's Struggle Against AIDS. PoPulation and develoPment review, 40, 447-473.

Anthropology, B.o.A.R.i. (2013). Final Impact Evaluation of the Saving for Change Program in Mali. Boston, MA: Oxfam America.

Asad, A.L., \& Kay, T. (2014). Theorizing the Relationship between NGOs and the State in Medical Humanitarian Development Projects. Social science \& medicine.

Bamberger, M., Rugh, J., \& Mabry, L. (2011). RealWorld evaluation: Working under budget, time, data, and political constraints: Sage publications.

Banerjee, A., Banerjee, A.V., \& Duflo, E. (2011). Poor economics: A radical rethinking of the way to fight global poverty: PublicAffairs.

Barnhoorn, F., \& Adriaanse, H. (1992). In search of factors responsible for noncompliance among tuberculosis patients in Wardha District, India. Social science \& medicine, 34, 291-306.

Becker, G., Gates, R.J., \& Newsom, E. (2004). Self-care among chronically ill African Americans: culture, health disparities, and health insurance status. American Journal of Public Health, 94, 2066.

Beckfield, J., Olafsdottir, S., \& Sosnaud, B. (2013). Healthcare Systems in Comparative Perspective: Classification, Convergence, Institutions, Inequalities, and Five Missed Turns. Annual Review of Sociology, 39, 127-146.

Bero, L.A., Grilli, R., Grimshaw, J.M., Harvey, E., Oxman, A.D., \& Thomson, M.A. (1998). Closing the gap between research and practice: an overview of systematic reviews of interventions to promote the implementation of research findings. Bmj, 317, 465-468.

Betancourt, J.R., Green, A.R., Carrillo, J.E., \& Ananeh-Firempong 2nd, O. (2003). Defining cultural competence: a practical framework for addressing racial/ethnic disparities in health and health care. Public health reports, 118, 293.

Borzekowski, D.L., \& Henry, H.K. (2010). The impact of Jalan Sesama on the educational and healthy development of Indonesian preschool children: An experimental study. International Journal of Behavioral Development, 0165025410380983.

Borzekowski, D.L., \& Macha, J.E. (2010). The role of $<\mathrm{i}>$ Kilimani Sesame $</ \mathrm{i}>$ in the healthy development of Tanzanian preschool children. Journal of Applied Developmental Psychology, 31, 298-305.

Camic, C., Gross, N., \& Lamont, M. (2012). Social knowledge in the making: University of Chicago Press.

Campbell, M., Fitzpatrick, R., Haines, A., Kinmonth, A.L., Sandercock, P., Spiegelhalter, D., et al. (2000). Framework for design and evaluation of complex interventions to improve health. BMJ: British Medical Journal, 321, 694. 
Castro, F.G., Barrera Jr, M., \& Martinez Jr, C.R. (2004). The cultural adaptation of prevention interventions: Resolving tensions between fidelity and fit. Prevention Science, 5, 41-45.

Céspedes, J., Briceño, G., Farkouh, M.E., Vedanthan, R., Baxter, J., Leal, M., et al. (2013). Targeting preschool children to promote cardiovascular health: cluster randomized trial. American Journal of Medicine, 126, 27-35.

Cockerham, W.C. (1981). Medical sociology. International Review of Modern Sociology, 231250.

Comunicación, C.e.I.y. (2009). Hábitos saludables para toda la vida: Summary of findings from impact assessment. Yucatán, México: CINCO.

Corrigan, P. (2004). How stigma interferes with mental health care. American Psychologist, 59, 614.

Delacollette, C., Van der Stuyft, P., \& Molima, K. (1996). Using community health workers for malaria control: experience in Zaire. Bulletin of the World Health Organization, 74, 423.

Devietti, E., \& Matuszeski, J. (2008). Saving for Change Program Assessment: El Salvador. Boston, MA: Oxfam America.

Dubbin, L.A., Chang, J.S., \& Shim, J.K. (2013). Cultural health capital and the interactional dynamics of patient-centered care. Social science \& medicine, 93, 113-120.

Farmer, P.E., Léandre, F., Mukherjee, J.S., Claude, M.S., Nevil, P., Smith-Fawzi, M.C., et al. (2001). Community-based approaches to HIV treatment in resource-poor settings. The Lancet, 358, 404-409.

Farmer, P.E., Nizeye, B., Stulac, S., \& Keshavjee, S. (2006). Structural violence and clinical medicine. PLoS Medicine, 3, e449.

Fay, H., Baral, S.D., Trapence, G., Motimedi, F., Umar, E., Iipinge, S., et al. (2011). Stigma, health care access, and HIV knowledge among men who have sex with men in Malawi, Namibia, and Botswana. AIDS and Behavior, 15, 1088-1097.

Fullwiley, D. (2007). The molecularization of race: institutionalizing human difference in pharmacogenetics practice. Science as Culture, 16, 1-30.

Furedi, F. (2006). The end of professional dominance. Society, 43, 14-18.

Geertz, C. (1973). The interpretation of cultures: Selected essays: Basic books.

Glanz, K., Rimer, B.K., \& Viswanath, K. (2008). Health behavior and health education: theory, research, and practice: John Wiley \& Sons.

Glaser, B.G., \& Strauss, A.L. (2009). The discovery of grounded theory: Strategies for qualitative research: Transaction Books.

Good, M.-J.D., Willen, S.S., Hannah, S.D., Vickery, K., \& Park, L.T. (2011). Shattering culture: American medicine responds to cultural diversity: Russell Sage Foundation.

Goodkind, J.R., Ross-Toledo, K., John, S., Hall, J.L., Ross, L., Freeland, L., et al. (2010). Promoting healing and restoring trust: Policy recommendations for improving behavioral health care for American Indian/Alaska Native adolescents. American journal of community psychology, 46, 386-394.

Helman, C.G. (2001). Culture, health and illness: Arnold, Hodder Headline Group.

Innovations, P. (2010). Eduational Impact of Galli Galli Sim Sim Mobile Community Viewing, Jaipur. Jaipur, India: Policy Innovations.

Israel, B.A., Coombe, C.M., Cheezum, R.R., Schulz, A.J., McGranaghan, R.J., Lichtenstein, R., et al. (2010). Community-based participatory research: a capacity-building approach for policy advocacy aimed at eliminating health disparities. American Journal of Public Health, 100, 2094-2102. 
Jerome, J., \& Ivers, L.C. (2010). Community health workers in health systems strengthening: a qualitative evaluation from rural Haiti. AIDS (London, England), 24, S67.

Kagawa-Singer, M., \& Kassim-Lakha, S. (2003). A strategy to reduce cross-cultural miscommunication and increase the likelihood of improving health outcomes. Academic Medicine, 78, 577-587.

Kleinman, A. (1978). Concepts and a model for the comparison of medical systems as cultural systems. Social Science \& Medicine. Part B: Medical Anthropology, 12, 85-93.

Kleinman, A. (1987). Anthropology and psychiatry. The role of culture in cross-cultural research on illness. The British Journal of Psychiatry, 151, 447-454.

Kleinman, A., Eisenberg, L., \& Good, B. (1978). Culture, illness, and careclinical lessons from anthropologic and cross-cultural research. Annals of internal medicine, 88, 251-258.

Kotler, J.A., Schiffman, J.M., \& Hanson, K.G. (2012). The influence of media characters on children's food choices. Journal of health communication, 17, 886-898.

Lamont, M., Beljean, S., \& Clair, M. (2014). What is missing? Cultural processes and causal pathways to inequality. Socio-Economic Review, mwu011.

Lamont, M., \& Molnár, V. (2002). The study of boundaries in the social sciences. Annual Review of Sociology, 167-195.

Lamont, M., \& Small, M.L. (2008). How culture matters: Enriching our understanding of poverty. The colors of poverty: Why racial and ethnic disparities persist, 76-102.

Liberati, A., Altman, D.G., Tetzlaff, J., Mulrow, C., Gøtzsche, P.C., Ioannidis, J.P., et al. (2009). The PRISMA statement for reporting systematic reviews and meta-analyses of studies that evaluate health care interventions: explanation and elaboration. Annals of internal medicine, 151, W-65-W-94.

Link, B.G., \& Phelan, J.C. (2006). Stigma and its public health implications. The Lancet, 367, 528-529.

Marmot, M. (2004). Status syndrome. Significance, 1, 150-154.

Metzl, J.M., \& Hansen, H. (2014). Structural competency: Theorizing a new medical engagement with stigma and inequality. Social science \& medicine, 103, 126-133.

Miles, M.B., \& Huberman, A.M. (1994). Qualitative data analysis: An expanded sourcebook: Sage.

Minkler, M., \& Wallerstein, N. (2011). Community-based participatory research for health: From process to outcomes: John Wiley \& Sons.

Patterson, O. (2004). Culture and continuity: Causal structures in socio-cultural persistence. Matters of culture: Cultural sociology in practice.

Patterson, O. (2014). Making Sense of Culture. Annual Review of Sociology, 40, 1-30.

Pescosolido, B.A., \& Olafsdottir, S. (2010). The Cultural Turn in Sociology: Can It Help Us Resolve an Age-Old Problem in Understanding Decision Making for Health Care? Sociological Forum pp. 655-676): Wiley Online Library.

Pescosolido, B.A., \& Olafsdottir, S. (2013). Beyond dichotomies: confronting the complexity of how and why individuals come or do not come to mental health care. World Psychiatry, $12,269$.

Phelan, J.C., Lucas, J.W., Ridgeway, C.L., \& Taylor, C.J. (2014). Stigma, status, and population health. Social science \& medicine, 103, 15-23.

Ritchie, L.D., Whaley, S.E., Spector, P., Gomez, J., \& Crawford, P.B. (2010). Favorable impact of nutrition education on California WIC families. Journal of nutrition education and behavior, 42, S2-S10. 
Rodríguez-Muñiz, M. (2015). Intellectual inheritances: Cultural diagnostics and the state of poverty knowledge. American Journal of Cultural Sociology, 3, 89-122.

Salant, T., \& Lauderdale, D.S. (2003). Measuring culture: a critical review of acculturation and health in Asian immigrant populations. Social science \& medicine, 57, 71-90.

Seidman, I. (2012). Interviewing as qualitative research: A guide for researchers in education and the social sciences: Teachers college press.

Shim, J.K. (2010). Cultural health capital a theoretical approach to understanding health care interactions and the dynamics of unequal treatment. Journal of Health and Social Behavior, 51, 1-15.

Swidler, A. (1986). Culture in action: Symbols and strategies. American Sociological Review, 273-286.

Trickett, E.J., Beehler, S., Deutsch, C., Green, L.W., Hawe, P., McLeroy, K., et al. (2011). Advancing the science of community-level interventions. American journal of public health, 101.

Vaisey, S. (2009). Motivation and Justification: A Dual-Process Model of Culture in Action1. American Journal of Sociology, 114, 1675-1715.

Vaisey, S. (2014). Is interviewing compatible with the dual-process model of culture. American Journal of Cultural Sociology, 2, 150-158.

Van Leeuwen, T. (2005). Introducing social semiotics: Psychology Press.

Viswanathan, M., Ammerman, A., Eng, E., Garlehner, G., Lohr, K.N., Griffith, D., et al. (2004). Community-based participatory research: Assessing the evidence: Summary. AHRQ Evidence Report Summaries. Rockville, MD: Agency for Healthcare Research and Quality.

Watkins, S.C., \& Swidler, A. (2013). Working misunderstandings: Donors, brokers, and villagers in Africa's AIDS industry. PoPulation and develoPment review, 38, 197-218.

Weiss, M.G. (2001). Cultural epidemiology: an introduction and overview. Anthropology \& Medicine, 8, 5-29.

Yin, R.K. (2009). Case study research: Design and methods: Sage. 